\title{
Burnout and Association with Psychosocial Work Environment among Swedish Firefighters
}

\author{
Ann Jacobsson ${ }^{1}$, Susann Backteman-Erlanson ${ }^{1}$ Mojgan Padyab ${ }^{2}$, Annika Egan Sjolander ${ }^{3} \&$ Christine Brulin $^{1}$ \\ ${ }^{1}$ Department of Nursing, Umea University, Umea, Sweden \\ ${ }^{2}$ Department of Social Work, Umea University, Umea, Sweden \\ ${ }^{3}$ Department of Culture and Media Studies, Umea University, Umea, Sweden \\ Correspondence: Ann Jacobsson, Department of Nursing, 901 87, Umea University, Umea, Sweden. Tel: \\ 46-90-786-6448. E-mail: ann.jacobsson@umu.se
}

Received: July 16, 2016 Accepted: September 7, 2016 Online Published: October 18, 2016

doi:10.5539/ghs.v9n5p214 URL: http://dx.doi.org/10.5539/gjhs.v9n5p214

\begin{abstract}
Firefighters are exposed to traumatic and stressful psychosocial and physical strain in their work, and thus they are considered to be a group at high risk of burnout. The aim of this study was to investigate burnout (emotional exhaustion (EE) and depersonalization (DP) among Swedish female and male firefighters and to examine the gender-stratified relationship between psychosocial work environment and burnout when considering the moderating effect of coping strategies among Swedish firefighters. The overall mean values of both EE and DP were notably low in comparison with the general population in Sweden. We found that psychosocial work environment factors increase the risk of burnout among male firefighters. Among men, EE was associated with high demands and lack of social support in work. The association was also confirmed with DP as the outcome and lack of good leadership as the exposure among men. However, among female firefighters the association between psychosocial work environment factors and burnout failed to appear. Among women, EE and DP were only associated with the coping strategy Psychological distancing (PDi). A negative association with DP and the coping strategy Positive Reappraisal (PRe) was also found among women. Regardless of the result from the regression analyses, we must consider that the majority of the female and male firefighters in our study had low scores on the outcome variables EE and DP. Future studies should explore female and male firefighters' context and possible health-protecting environment.
\end{abstract}

Keywords: burnout, coping strategies, firefighters, psychosocial work environment, Sweden

\section{Introduction}

Burnout is the commonly used term to describe a prolonged response to chronic psychosocial stressors in one's work. Over the past 30 years, researchers and practitioners have taken an increased interest in this topic and have revealed the complexity of the relationship between the individual's stress outcome and the individual's psychosocial work environment (Maslach, Schaufeli, \& Leiter, 2001; Stansfeld \& Candy, 2006). The most commonly used measure of burnout has been the Maslach Burnout Inventory (MBI), which was introduced in 1981 (Maslach, Jackson, \& Leiter, 1986; Schaufeli \& Enzmann, 1998). The prevalence of burnout differs between working populations and countries as well as due to differences in study designs (Schutte, Toppinen, Kalimo, \& Schaufeli, 2000). Among human-service professionals in Germany, a burnout prevalence rate of about 7-13\% was reported (Schaufeli \& Enzmann, 1998). The prevalence of burnout in the working population in Finland was shown to be $2.4 \%$ (Ahola et al., 2006). In Sweden, the prevalence was shown to vary between $13 \%$ and $17.9 \%$ (Lindblom, Linton, Fedeli, \& Bryngelsson, 2006; Magnusson Hanson, Theorell, Oxenstierna, Hyde, \& Westerlund, 2008; Norlund et al., 2010). Burnout is a multidimensional syndrome that occurs primarily in professions where the practitioners are working closely with people in intense and stressful interactions (Maslach et al., 2001; Norlund et al., 2010).

Firefighters and other first responders are exposed to traumatic and stressful psychosocial and physical strain in their work, and thus they are considered to be a group at high risk of burnout (Benedek, Fullerton, \& Ursano, 2007; Corneil, Beaton, Murphy, Johnson, \& Pike, 1999). In similar occupations in the Netherlands, such as ambulance personnel, the prevalence of burnout in workers from 10 regions was reported to be $8.6 \%$ (Van Der Ploeg \& Kleber, 
2003), and a study from a Scottish regional ambulance service reported that $26 \%$ and $22 \%$ of the workers had high scores on the MBI subscales of emotional exhaustion (EE) and depersonalization (DP), respectively (Sterud, Hem, Ekeberg, \& Lau, 2007). Among Swedish police personnel, high scores were reported for both EE (28\% of the personnel) and DP (56\% of the personnel) (Backteman-Erlanson, Padyab, \& Brulin, 2013). Research on the prevalence of burnout among firefighters in a larger population, however, is lacking. Of all the demographic variables that have been studied, age has been most consistently related to burnout (Maslach et al., 2001). The most common assumption is that burnout and exhaustion are more common among women and that they will score higher in burnout scales (Hallsten, Bellaagh, \& Gustafsson, 2002; Lindblom et al 2006; Lindert, Müller-Nordhorn, $\&$ Soares, 2009). However, the most consistent sex difference is that men often score higher on cynicism (Maslach, Leiter, \& Schaufeli, 2008; Maslach et al 2001; Ogus, Greenglass, \& Burke, 1990).

In an open-question study (Jacobsson, Backteman-Erlanson, Brulin, \& Hörnsten, 2015), female and male firefighters highlighted the emotional burden of being involved in critical incidents in their rescue work. The informants described traffic accidents, large fires, and other fatal incidents such as drowning and suicides as overwhelming. Intense work demands during emergencies puts both physical and psychological strain on the firefighters, and they need strategies to cope successfully (Chamberlin \& Green, 2010; Wagner \& Martin, 2012). To understand the relationship between work stress and burnout, the demand-and-control model is useful (Karasek \& Theorell, 1992). Stansfeld \& Candy (2006) and Lindblom et al. (2006) concluded that people with a high level of burnout report more work strain, lower control over their work environment, and less social support at work.

In the present study, we hypothesized that an insufficient psychosocial work environment increases the risk of burnout among firefighters. Moreover we hypothesized that the association between psychosocial work environment and burnout is moderated by coping strategies.

\subsection{Aim}

The aim of this study was to examine the gender-stratified relationship between psychosocial work environment and burnout among Swedish female and male firefighters when considering the moderating effect of coping strategies among Swedish firefighters.

\section{Method}

\subsection{Participants}

Out of 5,000 firefighters in Sweden working full time in emergency-response positions, 822 randomly selected Swedish male firefighters and all women working full time as firefighters in Sweden $(n=60)$ were invited by a letter to answer a questionnaire. The participants were identified through trade association records and through direct contact with those rescue stations not represented in the records. The final sample after four reminders consisted of 476 firefighters (418 men and 58 women) from all 290 districts and municipalities in Sweden. The mean \pm sd of the age of the sample was $41 \pm 10.2$ years, and the mean length of employment was $16 \pm 13.7$ years. A total of $388(82 \%)$ were married/living together (Table 1). The study was approved by the Regional Ethics Review Board in Umea, Sweden (No 08-186M).

\subsection{Assessment instruments}

The data collection started in January 2010 and ended in June 2011. The first section of the questionnaire included questions about the participants' demographic and work characteristics (sex, age, marital status, period of service, type of duty, and employment status) and lifestyle characteristics, including physical exercise, smoking, and drinking habits. The questionnaire with an additional request on whether or not they wanted to participate in the study was sent to the firefighters. Burnout was measured using the MBI consisting of the two main subscales of emotional exhaustion (EE) with nine items and depersonalization (DP) with five items (Bakker, Demerouti, \& Verbeke, 2004; Maslach et al., 2001). In this study, the Swedish version of the MBI was used (Hallsten et al., 2002). A Likert-scale was used for both subscales ranging from "never" (1) to "every day" (7). For both subscales, the total score was used giving an EE score ranging from 9 to 63 and a DP score ranging from 5 to 35 and with the following cutoffs. For the EE, scores of $\leq 16,17-27$, and $\geq 28$ were considered low, average, and high, respectively, and for the DP scores of $\leq 5,6-10$, and $\geq 11$ were considered low, average, and high, respectively.

The psychosocial work environment includes demand, control, and social support as well as the organizational environment (i.e., culture, climate, and leadership). Demand, control, and social support were measured using Karasek and Theorell's model (1992). Items on demand $(n=5)$ and control $(n=6)$ were responded to on a four-point scale ranging from "often" (1) to "never" (4), while items on social support $(n=6)$ were responded to on a four-point scale ranging from "agree completely" (1) to "do not agree at all" (4). A mean score for each subscale was calculated, and a higher score indicated higher psychological strain. Organizational environment was 
measured by three subscales from the General Nordic Questionnaire for Psychological and Social Factors at Work (QPS $\left.{ }_{\text {Nordic }}\right)$ (Dallner et al., 2000; Wännström, Peterson, Åsberg, Nygren, \& Gustavsson, 2009). The subscales used for this study were the organizational culture subscale (six items), the organizational climate subscale (five items), and the empowering and fair leadership subscale (eight items). Rating scales for each item varied between "very seldom" (1) and "very often or always" (5). For each subscale, mean scores were calculated based on the items within the subscale so as to provide an overall index score. Low scores were considered to be indicative of "good climate", while high values were considered to be indicative of "bad climate".

The Ways of Coping Questionnaire (WOCQ) instrument was used for assessing coping strategies. In this study a 40-item version of the WOCQ was used after Confirmatory Factor Analysis (CFA) and Exploratory Factor Analysis were performed. The suitability of the 40 -item version of the WOCQ in our sample was found to be satisfactory by CFA. The loading factors were high, and even the lowest loading factors exceeded the minimum acceptable value (which was 0.3$)$. The coping strategies were reported on a four-point Likert scale $(0=$ does not apply and/or not used; $1=$ used somewhat; $2=$ used quite a bit; and $3=$ used a great deal). The scores for each coping scale were calculated following the WOCQ manual (Folkman \& Lazarus, 1988). In the WOCQ, a high score indicates that the individual uses the behavior more often when coping with the specific stressful event.

\subsection{Statistical analysis}

For continuous variables, means and standard deviations were reported, and for nominal variables percentages were estimated. We used Student's $t$-test to compare the means \pm sd of the MBI subscale scores as well as psychosocial work environment, psychological demand, decision latitude, and social support between male and female firefighters. Effect size was also calculated for continuous variables to ensure not only statistical significance but also practical significance (Cohen, 1988). Cronbach's $\alpha$ values were calculated to ascertain the homogeneity of the items in each subscale (Table 1). The dependent variables were the total scores for the EE and DP subscales of the MBI. Independent variables were gender, age, years of employment, civil status, organizational culture, climate and leadership, psychological demand, control, and social support in work as well as coping strategies that were defined as potential moderators. Civil status was categorized into married/living together and single/divorced/other. Pearson correlation coefficients were calculated to assess the correlations between the MBI subscale scores and age, years of employment, organizational culture, climate and leadership, psychological demand, decision latitude, and social support. Hierarchical multiple regression analysis was used to investigate the relationship between the MBI subscales and psychosocial work environment, psychological demand, control, social support, and coping strategies (Table 3-6). All statistical analyses were conducted with SPSS version 22.

\section{Results}

The prevalence of burnout as well as demographics, work characteristics, and coping strategies among Swedish female and male firefighters are presented in Table 1. The average age was about 41 years for both men and women $(S D=10.2)$, while years of employment was significantly higher among men $(M=17$ years $)$ compared to women $(M=7$ years $)(p<0.001)$. Most participants were married/living together $(82 \%)$, but significantly more men $(85 \%)$ than women $(55 \%)$ were married/living together $(p<0.001)$. High levels of EE were found for $2 \%$ of women and $1 \%$ of men, and the corresponding proportions with high levels of DP were $2 \%$ for women and $3 \%$ for men. The mean value for EE did not differ significantly between women and men (17.8 vs. 17.94), but the mean value for DP was significantly lower among women than men $(6.9$ vs. $8.1, p<0.014)$. Social support was the only exposure variable that differed significantly between women and men $(1.7$ vs. $1.5, p<0.013)$. Women reported significantly higher use of all coping strategies except for Self-control (SCo), which was nearly the same as for men (Table 1).

Table 1. Descriptive statistics of individual characteristics, burnout, work-related psychosocial factors, physical symptoms, and coping strategies among female $(n=58)$ and male $(n=418)$ firefighters

\begin{tabular}{lllllll}
\hline & Total & Women & Men & P-value & $\boldsymbol{\eta}^{2}$ & $\begin{array}{l}\text { Cronbach's } \\
\boldsymbol{\alpha}\end{array}$ \\
\hline Age in years, M(SD) & $41(10.2)$ & $39(10,1)$ & $41(10.2)$ & .119 & & \\
Years of employment, M(SD) & $\mathbf{1 6 ( 1 3 . 7 )}$ & $\mathbf{7 ( 1 3 . 1 )}$ & $\mathbf{1 7}(\mathbf{1 3 . 3})$ & $<.001$ & -.72 & \\
Married/living together, $\boldsymbol{n} \%$ & $\mathbf{3 8 8}(\mathbf{8 2} \%)$ & $\mathbf{3 2 ( 5 5 \% )}$ & $\mathbf{3 5 5 ( 8 5 \% )}$ & $<.001$ & & \\
Smoking (no), $\boldsymbol{n} \%$ & $456(96.5 \%)$ & $56(97 \%)$ & $400(96 \%)$ & .208 & & \\
\hline
\end{tabular}




\begin{tabular}{|c|c|c|c|c|c|c|}
\hline \multicolumn{7}{|l|}{$M B I$} \\
\hline Emotional exhaustion, M(SD) & $17.93(6.09)$ & $17.85(6.94)$ & $17.94(5.99)$ & .917 & & .78 \\
\hline Low, $n \%$ & $410(90 \%)$ & $47(91 \%)$ & $362(90 \%)$ & & & \\
\hline Average, $n \%$ & $36(8 \%)$ & $4(7 \%)$ & $32(8 \%)$ & & & \\
\hline High, $n \%$ & $7(2 \%)$ & $1(2 \%)$ & $6(2 \%)$ & & & \\
\hline Depersonalization, M(SD) & $8.02(3.15)$ & $6.96(2.78)$ & $8.18(3.59)$ & .014 & -.33 & .60 \\
\hline Low, $n \%$ & $398(85 \%)$ & $54(93 \%)$ & $343(84 \%)$ & & & \\
\hline Average, $n \%$ & $57(12 \%)$ & $3(5 \%)$ & $54(13 \%)$ & & & \\
\hline High, $n \%$ & $13(3 \%)$ & $1(2 \%)$ & $12(3 \%)$ & & & \\
\hline \multicolumn{7}{|l|}{ JDCS } \\
\hline Demands, M(SD) & $2.60(.41)$ & $2.50(.41)$ & $2.61(.41)$ & .053 & -.26 & .61 \\
\hline Control, M(SD) & $1.93(.34)$ & $1.90(.32)$ & $1.93(.34)$ & .590 & & 43 \\
\hline Social support, M(SD) & $1.60(.44)$ & $1.74(.50)$ & $1.58(.43)$ & .013 & .36 & .81 \\
\hline \multicolumn{7}{|l|}{ QPS } \\
\hline Organizational culture, M (SD) & $2.87(.66)$ & $2.95(.73)$ & $2.86(.65)$ & .344 & & .65 \\
\hline Organizational climate, M (SD) & $2.64(.48)$ & $2.61(.46)$ & $2.65(.49)$ & .585 & & .78 \\
\hline Leadership, M(SD) & $3.02(.73)$ & $2.92(.88)$ & $3.04(.70)$ & 243 & & .86 \\
\hline \multicolumn{7}{|l|}{ WOCQ } \\
\hline Psychological distancing, M(SD) & $9.25(6.26)$ & $12.01(7.45)$ & $8.85(5.97)$ & .004 & .50 & .84 \\
\hline Planful problem solving, M(SD) & $15.05(4.23)$ & $16.39(3.98)$ & $14.88(4.23)$ & .012 & .36 & .77 \\
\hline Confrontative coping, $\mathrm{M}(\mathrm{SD})$ & $5.30(1.81)$ & $6.10(1.87)$ & $5.19(1.78)$ & .000 & .49 & .62 \\
\hline Wishful thinking, $\mathbf{M}(\mathrm{SD})$ & $3.74(2.60)$ & $5.34(2.45)$ & $3.50(2.54)$ & .000 & .70 & .68 \\
\hline Self-control, M(SD) & $5.68(1.74)$ & $5.81(1.87)$ & $5.66(1.72)$ & .527 & & .55 \\
\hline Positive reappraisal, M(SD) & $5.50(2.45)$ & $6.66(2.26)$ & $5.33(2.44)$ & .000 & .52 & .73 \\
\hline
\end{tabular}

$\mathrm{M}=$ mean value, $\mathrm{P}$-value indicates difference between men and women, $\eta^{2}$ effect size, and Cronbach`s $\alpha$ for total or subscale shows the internal consistency.

Table 2 presents the bivariate correlations between the dependent variable (EE score) and the independent variables included in the model. For both women and men, significant correlations were found between $\mathrm{EE}$ and the independent variables of demand, control, social support, organizational culture, climate, and leadership. Moreover, psychological distancing (PDi), wishful thinking (WTh), and positive reappraisal (PRe) were also significantly correlated with EE. Among women, the most prominent correlations were found between EE and high demand, lack of social support, and PDi. Among men, the strongest correlations were found between EE and high demand and lack of social support. The bivariate correlations between the other dependent variable DP and the independent variables showed a strongly significant correlation between DP and PDi among women. Among men, significant correlations were found between DP and lack of good leadership, lack of good organizational culture, lack of social support, and lack of good organizational climate (Table 2). 
Table 2. Bivariate correlation matrix for burnout as the dependent variable and its relationship with the independent variables of demand, control, social support, organizational culture, climate and leadership, and coping strategies among female $(n=58)$ and male $(n=418)$ fire fighters.

\begin{tabular}{|c|c|c|c|c|c|c|}
\hline & \multicolumn{3}{|c|}{ MBI Emotional exhaustion } & \multicolumn{3}{|c|}{ MBI Depersonalization } \\
\hline & Total & Women & Men & Total & Women & Men \\
\hline \multicolumn{7}{|l|}{$J D C S$} \\
\hline Demand & $0.382 * *$ & $0.535 * *$ & $0.364 * *$ & $0.137 * *$ & $0.306^{*}$ & $0.101 *$ \\
\hline Control & $0.160 * *$ & 0.141 & $0.162 * *$ & 0.019 & -0.149 & 0.040 \\
\hline Social support & $0.345 * *$ & $0.489 * *$ & $0.324 * *$ & $0.129 * *$ & 0.134 & $0.159 * *$ \\
\hline \multicolumn{7}{|l|}{$Q P S$} \\
\hline Organizational culture & $0.242 * *$ & $0.331 *$ & $0.227 * *$ & $0.167 * *$ & $0.291 *$ & $0.159 * *$ \\
\hline Organizational climate & $0.246 * *$ & $0.383 * *$ & $0.227 * *$ & $0.143 * *$ & 0.255 & $0.130 * *$ \\
\hline Leadership & $0.181 * *$ & $0.290 *$ & $0.161 * *$ & $0.202 * *$ & 0.206 & $0.198 * *$ \\
\hline \multicolumn{7}{|l|}{ WOCQ } \\
\hline Psychological distancing & $0.206 * *$ & $0.461 * *$ & $0.174 * *$ & $0.114 *$ & $0.492 * *$ & 0.095 \\
\hline Planful problem solving & 0.063 & -0.069 & 0.082 & -0.058 & -0.039 & -0.048 \\
\hline Confrontative coping & 0.052 & -0.085 & 0.074 & -0.045 & -0.003 & -0.037 \\
\hline Wishful thinking & $0.106 *$ & 0.008 & $0.124 *$ & 0.043 & 0.241 & 0.045 \\
\hline Self-control & 0.057 & -0.269 & $0.111 *$ & -0.079 & -0.237 & -0.062 \\
\hline Positive reappraisal & $0.100 *$ & -0.028 & $0.121 *$ & -0.063 & -0.075 & -0.041 \\
\hline
\end{tabular}

A high score for control indicates low control latitude, and a high score on social support indicates low social support. * Correlation is significant at the 0.05 level (2-tailed), ** Correlation is significant at the 0.01 level (2-tailed).

The results from the hierarchical multiple regression analysis are presented in Tables 3-6. The independent variables were entered into the hierarchical multiple regression in three steps. Demand, control, and social support were entered as the independent variables in the first step; organizational culture, climate, and leadership were entered in the second step; and coping factors were entered in the third step. The result among men showed that only demand and social support contributed significantly for predicting EE in the third step with a variance of $22 \%$ (Table 3).

Table 3. Multiple linear regression analysis of Emotional Exhaustion among Swedish male firefighters $(\mathrm{n}=418)$.

\begin{tabular}{|c|c|c|c|c|c|c|}
\hline & \multicolumn{2}{|l|}{ Model 1} & \multicolumn{2}{|l|}{ Model 2} & \multicolumn{2}{|l|}{ Model 3} \\
\hline & $\beta$ & Standardized $\beta$ & $\beta$ & Standardized $\beta$ & $\beta$ & Standardized $\beta$ \\
\hline \multicolumn{7}{|l|}{ JDCS } \\
\hline Demand & $4.458^{* * *}$ & $0.305 * * *$ & $4.412 * * *$ & $0.299 * * *$ & $4.560^{* * *}$ & $0.756 * * *$ \\
\hline Control $^{a}$ & $1.708^{*}$ & $0.831^{*}$ & $1.834^{*}$ & $0.101 *$ & $2.109 *$ & $0.930^{*}$ \\
\hline Social support ${ }^{\mathrm{b}}$ & $3.303 * * *$ & $0.666^{* * * *}$ & $3.533^{* * *}$ & $0.250 * * *$ & $2.953^{* *}$ & $0.848^{* *}$ \\
\hline \multicolumn{7}{|l|}{ QPS } \\
\hline Organization culture & & & 0.382 & 0.041 & 0.521 & 0.580 \\
\hline Organization climate & & & 0.370 & 0.030 & 0.615 & 0.755 \\
\hline Leadership & & & -0.690 & -0.080 & -0.851 & 0.505 \\
\hline \multicolumn{7}{|l|}{ WOCQ } \\
\hline Psychological distancing & & & & & 0.117 & 0.066 \\
\hline Planful problem & & & & & -0.093 & 0.103 \\
\hline
\end{tabular}




\begin{tabular}{llll}
\hline Confrontative coping & & 0.160 & 0.209 \\
Wishful thinking & & -0.044 & 0.141 \\
Self-control & & 0.260 & 0.218 \\
Positive reappraisal & & & 0.106 \\
$\mathbf{R}^{2}$ adjusted & 0.197 & 0.203 & 0.215
\end{tabular}

${ }^{\mathrm{a}}$ High scores for control indicate low control latitude. ${ }^{\mathrm{b}}$ High scores on social support indicate low social support. * $\mathrm{p}<0.05$, $* * \mathrm{p}<0.01, * * * \mathrm{p}=0.001$.

The corresponding analyses for women showed that only coping strategies (PDi) contributed significantly for predicting EE in the third step and accounted for $44 \%$ of the variance (Table 4 ).

Table 4. Multiple linear regression analysis of Emotional Exhaustion among Swedish female firefighters $(\mathrm{n}=58)$

\begin{tabular}{|c|c|c|c|c|c|c|}
\hline & \multicolumn{2}{|l|}{ Model 1} & \multicolumn{2}{|l|}{ Model 2} & \multicolumn{2}{|c|}{ Model 3} \\
\hline & $\beta$ & Standardized $\beta$ & $\beta$ & Standardized $\beta$ & $\beta$ & Standardized $\beta$ \\
\hline \multicolumn{7}{|l|}{$J D C S$} \\
\hline Demand & $8.179 * * *$ & $2.160 * * *$ & $7.975 * *$ & $0.457 * *$ & 2.768 & 0.182 \\
\hline Control $^{\mathrm{a}}$ & 2.412 & 2.780 & 2.587 & 0.116 & -2.965 & -0.157 \\
\hline Social support ${ }^{\text {b }}$ & $4.687 *$ & $1.932 *$ & 3.381 & 0.228 & 3.783 & 0.306 \\
\hline \multicolumn{7}{|l|}{$Q P S$} \\
\hline Organization culture & & & -0.130 & -0.014 & -1.362 & -0.171 \\
\hline Organization climate & & & 2.299 & 0.153 & 3.097 & 0.258 \\
\hline Leadership & & & 0.261 & 0.035 & -0.548 & -0.085 \\
\hline \multicolumn{7}{|l|}{ WOCQ } \\
\hline Psychological distancing & & & & & $0.250 *$ & $0.330 *$ \\
\hline Planful problem & & & & & -0.116 & -0.074 \\
\hline Confrontative coping & & & & & 0.139 & 0.047 \\
\hline Wishful thinking & & & & & 0.061 & 0.027 \\
\hline Self-control & & & & & -0.763 & -0.262 \\
\hline Positive reappraisal & & & & & -0.362 & -0.138 \\
\hline$R^{2}$ adjusted & 0.379 & & 0.350 & & 0.438 & \\
\hline
\end{tabular}

${ }^{a}$ High scores for control indicate low control latitude. ${ }^{\mathrm{b}}$ High scores on social support indicate low social support. $* \mathrm{p}<0.05$, $* * \mathrm{p}<0.01, * * * \mathrm{p}=0.001$.

In the hierarchical multiple regression with DP as the dependent variable, leadership contributed to the variance significantly, and of the coping strategies, PDi accounted for $5 \%$ of the variance of DP among men (Table 5).

Table 5. Multiple linear regression analysis of Depersonalization among Swedish male firefighters $(\mathrm{n}=418)$.

\begin{tabular}{|c|c|c|c|c|c|c|}
\hline & \multicolumn{2}{|l|}{ Model 1} & \multicolumn{2}{|c|}{ Model 2} & \multicolumn{2}{|c|}{ Model 3} \\
\hline & $\beta$ & Standardized $\beta$ & B & Standardized $\beta$ & $\beta$ & Standardized $\beta$ \\
\hline \multicolumn{7}{|l|}{$J D C S$} \\
\hline Demand & 0.575 & 0.066 & 0.303 & 0.034 & 0.336 & 0.038 \\
\hline Control $^{\mathrm{a}}$ & 0.045 & 0.004 & -0.115 & -0.011 & -0.291 & -0.027 \\
\hline Social support $^{\text {b }}$ & $1.206 * *$ & $0.143 * *$ & 0.540 & 0.063 & 0.480 & 0.056 \\
\hline
\end{tabular}




\begin{tabular}{lllll}
\hline $\boldsymbol{Q P S}$ & & & & \\
Organization culture & 0.313 & 0.055 & 0.111 & 0.020 \\
Organization climate & -0.041 & -0.006 & -0.024 & -0.003 \\
Leadership & $\mathbf{0 . 7 5 2 *}^{*}$ & $\mathbf{0 . 1 4 4 *}$ & $\mathbf{0 . 9 2 7 ^ { * * }}$ & $\mathbf{0 . 1 7 7 ^ { * * }}$ \\
\hline WOCQ & & & & \\
Psychological distancing & & $\mathbf{0 . 1 0 6 *}$ & $\mathbf{0 . 1 7 2 *}$ \\
Planful problem & & -0.013 & -0.015 \\
Confrontative coping & & 0.013 & 0.007 \\
Wishful thinking & & 0.033 & 0.23 \\
Self-control & & -0.091 & -0.042 \\
Positive reappraisal & & & -0.133 & -0.089 \\
$\boldsymbol{R}^{2}$ adjusted & 0.022 & & 0.047 & \\
\hline
\end{tabular}

${ }^{\mathrm{a}} \mathrm{High}$ scores for control indicate low control latitude. ${ }^{\mathrm{b}}$ High scores on social support indicate low social support. * $\mathrm{p}<0.05,{ }^{* *}$ $\mathrm{p}<0.01,{ }^{* * *} \mathrm{p}=0.001$.

The corresponding analyses among women with DP as the dependent variable showed that only PDi contributed significantly to DP in the third step of the regression and accounted for $36 \%$ of the variance. PRe was negatively associated with DP among women, which was interpreted to mean that less use of "positive appraisal" is related to higher DP (Table 6).

Table 6. Multiple linear regression analysis of Depersonalization among Swedish female firefighters $(\mathrm{n}=58)$.

\begin{tabular}{|c|c|c|c|c|c|c|}
\hline & \multicolumn{2}{|c|}{ Model 1} & \multicolumn{2}{|c|}{ Model 2} & \multicolumn{2}{|l|}{ Model 3} \\
\hline & $\beta$ & Standardized $\beta$ & B & Standardized $\beta$ & $\beta$ & Standardized $\beta$ \\
\hline \multicolumn{7}{|l|}{ JDCS } \\
\hline Demand & 1.756 & 0.258 & 1.599 & 1.730 & 1.201 & 0.168 \\
\hline Control $^{\mathrm{a}}$ & -1.459 & -0.165 & -1.404 & -1.071 & -1.121 & -0.118 \\
\hline Social support ${ }^{b}$ & 0.942 & 0.166 & -0.209 & -0.200 & -1.594 & -0.279 \\
\hline \multicolumn{7}{|l|}{ QPS } \\
\hline Organization culture & & & 0.991 & 1.277 & 0.938 & 0.240 \\
\hline Organization climate & & & 0.819 & 0.800 & 1.113 & 0.189 \\
\hline Leadership & & & -0.147 & -0.262 & 0.084 & 0.026 \\
\hline \multicolumn{7}{|l|}{ WOCQ } \\
\hline Psychological distancing & & & & & $0.200^{* * * *}$ & $0.525 * * *$ \\
\hline Planful problem & & & & & 0.178 & 0.230 \\
\hline Confrontative coping & & & & & -0.120 & -0.081 \\
\hline Wishful thinking & & & & & 0.42 & 0.037 \\
\hline Self-control & & & & & -0.046 & -0.032 \\
\hline Positive reappraisal & & & & & $-0.554 *$ & $-0.418^{*}$ \\
\hline$R^{2}$ adjusted & 0.071 & & 0.087 & & 0.364 & \\
\hline
\end{tabular}

${ }^{\mathrm{a}} \mathrm{High}$ scores for control indicate low control latitude. ${ }^{\mathrm{b}}$ High scores on social support indicate low social support. * $\mathrm{p}<0.05$, $* * \mathrm{p}<0.01, * * * \mathrm{p}=0.001$. 


\section{Discussion}

In the present study, we investigated burnout among Swedish female and male firefighters. The aim was to examine the gender-stratified relationship between psychosocial work environment and burnout when considering the moderating effects of coping strategies among Swedish firefighters. The results seem to confirm that there is a positive association between psychosocial factors in the work environment and burnout among men, but not among women. The results of the hierarchical regression models (step 3) confirm the moderating effect of coping strategies. The coping strategies among firefighters influence the level of burnout, and these strategies are different between women and men.

The overall low value in the burnout scales (EE and DP) among both women and men in our study was notable. Only about $3 \%$ of the Swedish firefighters in this study scored high, which is in contrast to the general population in Sweden where nearly $20 \%$ have been reported to belong to the high-scoring group (Lindblom et al., 2006). In a recent study among Swedish healthcare personnel, about 30\% scored high in EE, and about 14\% scored high in DP (Åhlin, Ericson - Lidman, Norberg, \& Strandberg, 2015). Among ambulance service personnel in Scotland, 25\% scored high in EE (Alexander \& Klein, 2001). The levels of both EE and DP in our study were also lower than in a similar study among police personnel in Sweden, where $28 \%$ of the personnel reported high scores in EE and $56 \%$ of the personnel reported high scores in DP (Backteman-Erlanson et al., 2013). Despite the fact that the mean value for the burnout scales EE and DP were low among firefighters in this study, it should be mentioned that the mean value for DP among male firefighters was significantly higher than among female firefighters. Among Swedish police personnel (Backteman-Erlanson et al., 2013), the mean value for DP was also significantly higher for men than for women. These results are also consistent with other studies that report men to have higher levels of DP than women (Houkes, Winants, Twellaar, \& Verdonk, 2011). This result is also comparable to established research in the field (Bakker, Demerouti, \& Schaufeli, 2002; Emmerik \& Euwema, 2001; Maslach et al., 2001; Schaufeli \& Enzmann, 1998). Maslach, et al. (2001) reported that there is a tendency for women to have higher levels of EE than men, whereas men tend to have higher levels of DP than women. This result is also consistent with gender role theory, which predicts that women more often process events using emotion-focused coping that can result in high EE. Men are more likely to shut off (avoidance) and withdraw (confrontative coping) under stress, which might lead to high DP (Eagly, 2013; Purvanova \& Muros, 2010).

There are undoubtedly several stressful situations when working as a firefighter, including fires, traffic accidents, and the threat of personal injury or death. In this study we found that psychosocial work environment factors increase the risk of burnout among male firefighters according to the associations between EE and high demand and lack of social support. The association was also confirmed among men in the hierarchical multiple regression models with DP as the outcome and lack of good leadership as the exposure. Our findings are consistent to some degree with results from research stating that firefighters are exposed to high demands in their work, and thus they are considered to be a group at risk of burnout (Benedek et al., 2007). However, the reported low level of burnout is somewhat surprising because we know what firefighters are exposed to and we know how the level of burnout is related to similar exposures among other kinds of first responders (Backteman-Erlanson et al., 2013; Sterud et al., 2007). However, among female firefighters the association between psychosocial work environment factors and burnout failed to appear. Studies supporting this result are lacking, and thus we have few comparisons for our data. In fact, research on the prevalence of burnout among firefighters as a whole is lacking, and we have not found any studies reporting results for female and male firefighters separately. However, it has been shown elsewhere that females in male-dominated professions might have additional struggles with their status as a minority (Häyrén Weinestål, Bondestam, \& Berg, 2011). This lack of studies also highlights the gap in knowledge and encourages future studies, both of the group as a whole and separately for female and male firefighters as well as in comparison to other similar professions.

Regardless of the result from the regression analysis, we must consider that the majority of the female and male firefighters in our study had low scores on the outcome variables EE and DP. The presence of health-protecting factors such as individual and organizational resources can be possible explanations for these results, and individual resources might be explained in part by coping mechanisms (Sattler, Boyd, \& Kirsch, 2014). In a study among firefighters in Dublin, male firefighters had developed adaptive coping mechanisms that protected against symptoms of psychological distress (Bevin, 2013). Landen \& Wang (2010) emphasized the role that resources can play in contributing to the well-being of firefighters with high job demands. Organizational resources provide a unique opportunity to develop strong bonds with co-workers not only during work-related tasks but also through everyday activities at the same fire station for an extended period of time (Ericson, 2011; Häyrén Weinestål et al., 2011; Landen \& Wang, 2010). Firefighters have unique preconditions to develop working relationships and emotional connections, and higher degrees of work cohesion have been found to be significantly associated with 
decreased anxiety during emergencies. Other positive effects are successful decision making, greater effectiveness in responding to emergencies, a greater ability to cope with post-emergency experiences, and increased psychological well-being (Beaton, Murphy, Johnson, Pike, \& Cornell, 1998; Fullerton, McCarroll, Ursano, \& Wright, 1992; Landen \& Wang, 2010; North et al., 2002).

Low social support was also a significant predictor for EE among men in this study. This is consistent with both empirical research (Bakker et al., 2002; Töyry et al., 2004) and theoretical assumptions that social support might have a buffering effect on the development of burnout (Maslach, 2001). However, the consideration of work characteristics without an understanding of their social structural context has been criticized from a sociological perspective. Social hierarchies, and the implicit power relationships among them, influence the distribution of work-related stressors and support and even influence factors such as self-esteem. Moreover, the effects of work characteristics on mental health might be partly conveyed through the symbolic meaning of work-related stressors that can be understood in the context of power relationships that pertain to a particular occupational setting (Brooker \& Eakin, 2001).

Coping strategies among firefighters are associated with burnout, and there are gender differences in this association. The level of PDi was significantly higher for women than men, and the level of PDi was also higher in all other coping scales except SCo. DP was negatively associated with PRe - which leads to focusing on personal growth in an effort to create positive meaning (Lazarus, 1993) - among the female participants. In this study, however, the negative association suggests that the lower PRe is associated with greater DP. Another association was found between burnout and the PDi coping strategy, and both EE and DP were significantly associated with PDi among the female firefighters (Table 4, Table 6). As we mentioned earlier, in addition to the stress of the profession itself, women in a male-dominated profession might also need strategies to deal with their status as a minority and to deal with the increased pressure to succeed in a male-dominated environment (Chetkovich, 2004). A possible link can be drawn between this finding and the study of Swedish firefighters involved in critical incidents in their rescue work (Jacobsson et al., 2015), where women were shown to take a more distanced, descriptive, and abstracted position compared to men.

\subsection{Methodological Considerations}

A strength of this study was that almost all women responded, which was in contrast to the moderate response rate among the male participants. With regard to the differences between women and men in this study, a problem with studying sex differences in a male-dominated profession is that the sample sizes for females are generally small resulting in poor power to detect small differences between the sexes (Greenglass, 1991; Greenglass, Burke, \& Ondrack, 1990; Grossi, Perski, Evengård, Blomkvist, \& Orth-Gomér, 2003; Houkes et al., 2011). Another strength of this study is that comparability is ensured because the instrument used in this study is one that is commonly used by researchers in occupational health in different contexts (Backteman-Erlanson et al., 2013; Lindeberg et al., 2010; Staland-Nyman, Alexanderson, \& Hensing, 2008). All instruments used in this study have been tested for validity and reliability.

A limitation of this study was the cross-sectional design, which means that no causal inferences could be made. Complementary studies to determine causation of firefighters' work-related health is a proposal for further research, and such research should focus especially on supportive resources.

\section{Conclusion}

There are indications that Swedish firefighter's mental health is generally good. Consistent results in this direction are reported in Arnetz's (2012) study of work-related stress and its impact on first responders such as police personnel, firefighters, military personnel, the coast guard, and customs officials in Sweden. In Arnetz's study (2012), firefighters were the healthiest profession in several respects, particularly in relation to police officers who reported more negative consequences from their work-related stress. Because comparable professions have differences in outcomes such as fatigue symptoms and cynicism (Backteman-Erlanson et al., 2013; Elmqvist, Brunt, Fridlund, \& Ekebergh, 2010), it would be interesting for future studies to explore the firefighters' context and possible health-protecting environment. For example, there are studies that support the hypothesis that the social position and the social support that individuals receive from their work environment and society is an important aspect for maintaining health (Karasek \& Theorell, 1992; Stansfeld \& Candy, 2006).

\section{Competing Interests Statement}

The authors declare that there is no conflict of interests regarding the publication of this paper. 


\section{References}

Åhlin, J., Ericson - Lidman, E., Norberg, A., \& Strandberg, G. (2015). A comparison of assessments and relationships of stress of conscience, perceptions of conscience, burnout and social support between healthcare personnel working at two different organizations for care of older people. Scandinavian Journal of Caring Sciences, 29(2), 277-287. http://dx.doi.org/10.1111/scs.12161

Ahola, K., Honkonen, T., Isometsä, E., Kalimo, R., Nykyri, E., Koskinen, S., . . Lönnqvist, J. (2006). Burnout in the general population. Social Psychiatry and Psychiatric Epidemiology, 41(1), 11-17. http://dx.doi.org/10.1007/s00127-005-0011-5

Alexander, D. A., \& Klein, S. (2001). Ambulance personnel and critical incidents. Impact of accident and emergency work on menatal health and emotional well-being. British Journal of Psychiatry, 178, 76-81. http://dx.doi.org/10.1192/bjp.178.1.76

Arnetz, B. (2012). "Det här är inte vilket yrke som helst!” Yrkespåförd stress, hälsa och prestation hos operativt verksamma inom brandförsvaret, försvarsmakten, kustbevakningen, polisen och tullverket. Resultat från nationell enkätkartläggning. Department of Public Health and Caring Sciences, Uppsala University, Sweden.

Backteman-Erlanson, S., Padyab, M., \& Brulin, C. (2013). Prevalence of burnout and associations with psychosocial work environment, physical strain, and stress of conscience among Swedish female and male policepersonnel. Police Practice and Research, 14(6), 491-505. http://dx.doi.org/10.1080/15614263.2012.736719

Bakker, A. B., Demerouti, E., \& Schaufeli, W. B. (2002). Validation of the Maslach burnout inventory-general

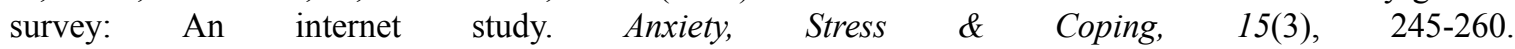
http://dx.doi.org/10.1080/1061580021000020716

Bakker, A. B., Demerouti, E., \& Verbeke, W. (2004). Using the job demands-resources model to predict burnout and performance. Human Resource Management, 43(1), 83-104. http://dx.doi.org/10.1002/hrm.20004

Beaton, R., Murphy, S., Johnson, C., Pike, K., \& Cornell, W. (1998). Exposure to Duty-Related Incident Stressors in Urban Firefighters and Paramedics. Journal of Traumatic Stress, 11(4), 821-828. http://dx.doi.org/10.1023/A:1024461920456

Benedek, D. M., Fullerton, C., \& Ursano, R. J. (2007). First Responders: Mental Health Consequences of Natural and Human-Made Disasters for Public Health and Public Safety Workers*. Annual Review of Public Health, 28, 55-68. http://dx.doi.org/10.1146/annurev.publhealth.28.021406.144037

Bevin, H. (2013). A qualitative exploration of traumatic experiences and coping strategies amongst firefighters in Dublin Fire Brigade and their attitudes to support services. Thesis submitted in partial fulfilment of the requirements of the BA Counselling and Psychotherapy, Dublin Business School

Brooker, A. S., \& Eakin, J. M. (2001). Gender, class, work - related stress and health: toward a power - centred approach. Journal of Community \& Applied Social Psychology, 11(2), 97-109. http://dx.doi.org/10.1002/casp.620

Chamberlin, M. J., \& Green, H. J. (2010). Stress and coping strategies among firefighters and recruits. Journal of Loss and Trauma, 15(6), 548-560. http://dx.doi.org/10.1080/15325024.2010.519275

Chetkovich, C. (2004). Women's agency in a context of oppression: Assessing strategies for personal action and public policy. Hypatia, 19(4), 122-143. http://dx.doi.org/10.1111/j.1527-2001.2004.tb00151.x

Cohen, J. (1988). Statistical power analysis for the behavior science. Lawrance Eribaum Association.

Corneil, W., Beaton, R., Murphy, S., Johnson, C., \& Pike, K. (1999). Exposure to traumatic incidents and prevalence of posttraumatic stress symptomatology in urban firefighters in two countries. Journal of Occupational Health Psychology, 4(2), 131. http://dx.doi.org/10.1037/1076-8998.4.2.131

Dallner, W., Elo, A. L., Gamberale, F., Hottinen, V., Knardahl, S., \& Lindström, K. (2000). Validation of the general Nordic questionnaire (QPSNordic) for psychological and social factors at work In C. N. C. o. Ministers (Ed.), No. Nord 2000:12.

Eagly, A. H. (2013). Sex differences in social behavior: A social-role interpretation. New Jersey: Hillsdal.

Elmqvist, C., Brunt, D., Fridlund, B., \& Ekebergh, M. (2010). Being first on the scene of an accident--experiences of 'doing' prehospital emergency care. Scandinavian Journal of Caring Sciences, 24(2), 266-273. http://dx.doi.org/10.1111/j.1471-6712.2009.00716.x 
Emmerik, I., \& Euwema, M. (2001). At risk of burnout: Gender and faculty differences within academia. Rainer Hampp Verlag

Ericson, M. (2011). Nära inpå. Maskulinitet, intimitet och gemenskap i brandmäns arbetslag. Thesis, Göteborg Studies in Sociology, Göteborga University

Folkman, S., \& Lazarus, R. S. (1988). Manual for the ways of coping questionnaire. Consulting Psychologists Press.

Fullerton, C. S., McCarroll, J. E., Ursano, R. J., \& Wright, K. M. (1992). Psychological responses of rescue workers: fire fighters and trauma. American Journal of Orthopsychiatry, 62(3), 371. http://dx.doi.org/10.1037/h0079363

Greenglass, E. R. (1991). Burnout and gender: Theoretical and organizational implications. Canadian Psychology/Psychologie canadienne, 32(4), 562. http://dx.doi.org/10.1037/h0079042

Greenglass, E. R., Burke, R. J., \& Ondrack, M. (1990). A Gender - role Perspective of Coping and Burnout. Applied psychology, 39(1), 5-27. http://dx.doi.org/10.1111/j.1464-0597.1990.tb01035.x

Grossi, G., Perski, A., Evengård, B., Blomkvist, V., \& Orth-Gomér, K. (2003). Physiological correlates of burnout among women. Journal of Psychosomatic Research, 55(4), 309-316. http://dx.doi.org/10.1016/S0022-3999 (02)00633-5

Hallsten, L., Bellaagh, K., \& Gustafsson, K. (2002). Utbränning i Sverige: en populationsstudie. Stockholm: National Institute for Working Life.

Häyrén Weinestål, A., Bondestam, F., \& Berg, H. (2011). Från novis till nestor Maskulinitet organsation och risk $i$ räddningstjänsten En aktionsforskningsstudie. Myndigheten för samhällsskydd och beredskap, Karlstad.

Houkes, I., Winants, Y., Twellaar, M., \& Verdonk, P. (2011). Development of burnout over time and the causal order of the three dimensions of burnout among male and female GPs. A three-wave panel study. BMC Public Health, 11(1), 1. http://dx.doi.org/10.1186/1471-2458-11-240

Jacobsson, A., Backteman-Erlanson, S., Brulin, C., \& Hörnsten, Å. (2015). Experiences of critical incidents among female and male firefighters. International Emergency Nursing, 23(2), 100-104. http://dx.doi.org/10.1016/j.ienj.2014.06.002

Karasek, R. A., \& Theorell, T. (1992). Healthy work: stress, productivity, and the reconstruction of working life. New York: Basic books.

Landen, S. M., \& Wang, C.-C. D. C. (2010). Adult attachment, work cohesion, coping, and psychological well-being of firefighters. Counselling Psychology Quarterly, 23(2), $143-162$. http://dx.doi.org/10.1080/09515071003776028

Lazarus, R. S. (1993). Coping Theory and Research: Past, Present, and Future. Psychosomatic Medicine, 55, 234-247. http://dx.doi.org/10.1097/00006842-199305000-00002

Lindblom, K. M., Linton, S. J., Fedeli, C., \& Bryngelsson, L. (2006). Burnout in the working population: relations to psychosocial work factors. International Journal of Behavioral Medicine, 13(1), 51-59. http://dx.doi.org/10.1207/s15327558ijbm1301_7

Lindeberg, S., Rosvall, M., Choi, B., Canivet, C., Isacsson, S.-O., Karasek, R., \& Östergren, P.-O. (2010). Psychosocial working conditions and exhaustion in a working population sample of Swedish middle-aged men and women. European Journal of Public Health, 21(2), 190-196. http://dx.doi.org/10.1093/eurpub/ckq039

Lindert, J., Müller-Nordhorn, J., \& Soares, J. F. (2009). Age and distress of women-results of a representative population-based study. Archives of women's mental health, 12(3), 173-181. http://dx.doi.org/10.1007/s00737-009-0051-z

Magnusson Hanson, L. L., Theorell, T., Oxenstierna, G., Hyde, M., \& Westerlund, H. (2008). Demand, control and social climate as predictors of emotional exhaustion symptoms in working Swedish men and women. Scandinavian journal of public health, 36(7), 737-743. http://dx.doi.org/10.1177/1403494808090164

Maslach, C. (2001). What have we learned about burnout and health? Psychology \& Health, 16(5), 607-611. http://dx.doi.org/10.1080/08870440108405530

Maslach, C., Jackson, S. E., \& Leiter, M. P. (1996). Maslach Burnout Inventory (3rd ed.). Palo Alto: CA: Consulting psychologists press. 
Maslach, C., Leiter, M. P., \& Schaufeli, W. (2008). Measuring burnout. In C. L. Cooper \& S. Cartwright (Eds.), The Oxford Handbook of Organizational Wellbeing. Oxford: Oxford University Press. http://dx.doi.org/10.1093/oxfordhb/9780199211913.003.0005

Maslach, C., Schaufeli, W. B., \& Leiter, M. P. (2001). Job burnout. Annual Review of Psychology, 52(1), 397-422. http://dx.doi.org/10.1146/annurev.psych.52.1.397

Norlund, S., Reuterwall, C., Höög, J., Lindahl, B., Janlert, U., \& Birgander, L. S. (2010). Burnout, working conditions and gender-results from the northern Sweden MONICA Study. BMC Public Health, 10(1), 1. http://dx.doi.org/10.1186/1471-2458-10-326

North, C. S., Tivis, L., McMillen, J. C., Pfefferbaum, B., Cox, J., Spitznagel, E. L., . . Smith, E. M. (2002). Coping, functioning, and adjustment of rescue workers after the Oklahoma City bombing. Journal of Traumatic Stress, 15(3), 171-175. http://dx.doi.org/10.1023/A:1015286909111

Ogus, E. D., Greenglass, E. R., \& Burke, R. J. (1990). Gender-role differences, work and stress and depersonalization. Journal of Social Behavior and Personality, 5, 387-398.

Purvanova, R. K., \& Muros, J. P. (2010). Gender differences in burnout: A meta-analysis. Journal of Vocational Behavior, 77(2), 168-185. http://dx.doi.org/10.1016/j.jvb.2010.04.006

Sattler, D. N., Boyd, B., \& Kirsch, J. (2014). Trauma - exposed Firefighters: Relationships among Posttraumatic Growth, Posttraumatic Stress, Resource Availability, Coping and Critical Incident Stress Debriefing Experience. Stress and Health, 30(5), 356-365. http://dx.doi.org/10.1002/smi.2608

Schaufeli, W., \& Enzmann, D. (1998). The burnout companion to study and practice: A critical analysis. London Taylor \& Francis Ltd.

Schutte, N., Toppinen, S., Kalimo, R., \& Schaufeli, W. (2000). The factorial validity of the Maslach Burnout Inventory - General Survey (MBI - GS) across occupational groups and nations. Journal of Occupational and Organizational Psychology, 73(1), 53-66. http://dx.doi.org/10.1348/096317900166877

Staland-Nyman, C., Alexanderson, K., \& Hensing, G. (2008). Associations between strain in domestic work and self-rated health: A study of employed women in Sweden. Scandinavian journal of public health, 36, 21-27. http://dx.doi.org/10.1177/1403494807085307

Stansfeld, S., \& Candy, B. (2006). Psychosocial work environment and mental health - a meta-analytic review. Scandinavian Journal of Work, Environment and Health, 443-462. http://dx.doi.org/10.5271/sjweh.1050

Sterud, T., Hem, E., Ekeberg, Ø., \& Lau, B. (2007). Occupational stress and alcohol use: a study of two nationwide samples of operational police and ambulance, personnel in Norway. Journal of studies on alcohol and drugs, 68(6), 896-904. http://dx.doi.org/10.15288/jsad.2007.68.896

Töyry, S., Kalimo, R., Äärimaa, M., Juntunen, J., Seuri, M., \& Räsänen, K. (2004). Children and work - related stress among physicians. Stress and Health, 20(4), 213-221. http://dx.doi.org/10.1002/smi.1009

Van Der Ploeg, E., \& Kleber, R. J. (2003). Acute and chronic job stressors among ambulance personnel: predictors of health symptoms. Occupational and Environmental Medicine, 60(suppl 1), i40-i46. http://dx.doi.org/10.1136/oem.60.suppl_1.i40

Wagner, S. L., \& Martin, C. A. (2012). Can Firefighters' Mental Health Be Predicted by Emotional Intelligence and Proactive Coping? Journal of Loss and Trauma, 17(1), 56-72. http://dx.doi.org/10.1080/15325024.2011.584027

Wännström, I., Peterson, U., Åsberg, M., Nygren, Å., \& Gustavsson, J. P. (2009). Psychometric properties of scales in the General Nordic Questionnaire for Psychological and Social Factors at Work (QPSNordic): Confirmatory factor analysis and prediction of certified long - term sickness absence. Scandinavian Journal of Psychology, 50(3), 231-244. http://dx.doi.org/10.1111/j.1467-9450.2008.00697.

\section{Copyrights}

Copyright for this article is retained by the author(s), with first publication rights granted to the journal.

This is an open-access article distributed under the terms and conditions of the Creative Commons Attribution license (http://creativecommons.org/licenses/by/4.0/). 